\title{
Comparison of equivalent beam models and refined approaches for the modelling of masonry portal frames
}

\author{
C. Mordant \\ University of Liège, Liege, Belgium \\ H. Degée \& B. Vandoren \\ Hasselt University, Diepenbeek, Belgium
}

\begin{abstract}
The recent evolutions in the analysis and design of masonry structures tend to let consider these structures at the same level as the more traditionally engineered materials, namely steel and concrete, as far as it comes to the refinement of the analysis and of the control of the failure modes in the framework of a limit-state design approach. Such an evolution comes together with the development of reliable analysis tools. In this context, the most promising approach whose use could reasonably be generalized in regular design offices for the analysis of full buildings is the use of equivalent beams to model walls and spandrels, resulting in a global frame modelling approach of entire structures. Such models need however to be properly calibrated regarding a large number of aspects such as deformation properties, resistance models, behaviour of the nodes, lintels, spandrels... The proposed paper aims at illustrating such a calibration process. It starts from experimental results achieved at the University of Liege on small clay masonry structures made of two walls connected by a spandrel, with a RC lintel over the door opening and a RC beam emulating the presence of a concrete slab at the first floor level. The tests specimens are then modelled using a refined finite element approach and compared with a frame modelling considering the vertical and horizontal structural elements as equivalent columns and beams.
\end{abstract}

\section{INTRODUCTION}

Unreinforced masonry is one of the most common and widespread way to build private dwellings in North-Western Europe. Since the 1973 energy crisis, the demand in terms of building physics performances has progressively increased until the creation of "passive houses" concept at the end of the last century, leading to the raise of new structural challenges and to the necessary development of appropriate technical solutions. This has led to progressively consider masonry at the same level as other more traditionally engineered materials such as steel or concrete. These evolution in the analysis and design of masonry structures goes together with an obvious refinement of the analysis tools and of the control of the failure modes in the framework of a limit-state design approach, such as implemented in Eurocode 6. This evolution requires of course the development of reliable analysis tools. In this context, the most promising method whose use could reasonably be generalized in regular design offices for the analysis of entire buildings is the use of equivalent beams to model walls, lintels and spandrels, resulting in global equivalent frames to model entire structures (see for instance Beyer et al,
2013, and Lagomarsino et al, 2013). Such models need however to be properly calibrated regarding a large number of aspects such as deformation properties, resistance models, behaviour of the nodes, lintels, spandrels (da Porto et al, 2010)... Advanced finite element software packages may alternatively be used for such an analysis, although their use remains often limited to a research context (see for instance Adessi et al, 2010).

The present paper aims at illustrating different aspects of such a modelling, referring as main point of comparison to the results of some recent experimental tests carried out at University of Liège.

\section{REFERENCE EXPERIMENTAL RESULTS}

\subsection{Test specimen}

The reference experimental results considered hereby are part of a set of cyclic tests on $3 \times 2.8$ m masonry panels with a door opening (see Fig. 1 and 2). Tests are performed on thin-bed layered unreinforced load-bearing clay masonry walls with glued horizontal joints and empty vertical ones. The specimens are first subjected to a global vertical compression 


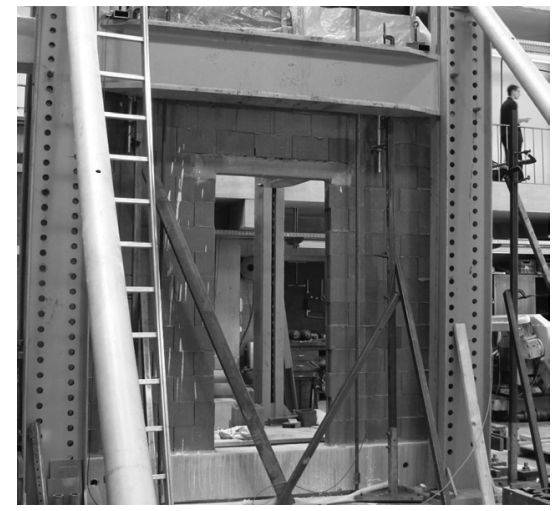

Figure 1. Test specimen (picture).

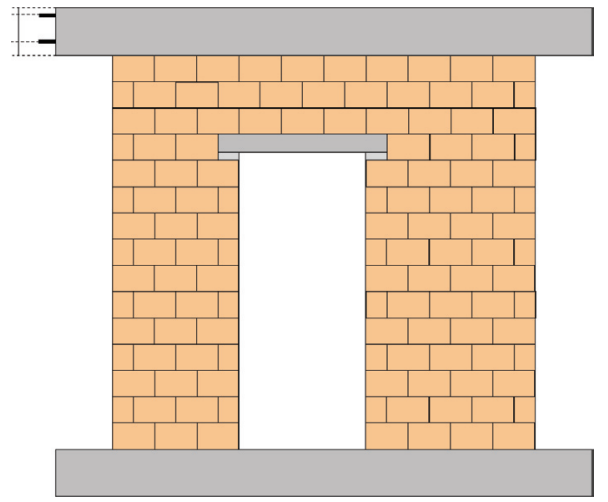

Figure 2. Test specimen (drawing).

then to alternated horizontal cycles (displacementcontrolled) with progressively increasing amplitude. The main characteristics are as follows:

- Length:

- Height:

$3000,0 \mathrm{~mm}$

$2800,0 \mathrm{~mm}$

- Thickness:

$139,6 \mathrm{~mm}$

- Average pre-compression level: 1,0 MPa

- Length opening:

- Height opening:

- Length left pier:

$900,0 \mathrm{~mm}$

$2000,0 \mathrm{~mm}$

$900,0 \mathrm{~mm}$

- Length right pier:

$1200,0 \mathrm{~mm}$

Mechanical properties of the units and of the masonry are:

- Normalized compressive stress of the units, according to EN 772-1 annex A

$f_{b}=13.0 \mathrm{~N} / \mathrm{mm}^{2}$

- Measured characteristic masonry compressive strength of wallets according to EN 1052-1

$f_{k}=5.6 \mathrm{~N} / \mathrm{mm}^{2}$
- Characteristic compressive strength of the masonry obtained from unit resistance according to EN 1996-1-1

$f_{k}=4.2 \mathrm{~N} / \mathrm{mm}^{2}$

- Characteristic compressive strength of the masonry obtained from unit resistance according to NBN-EN 1996-1-1 (Belgian National Annex to Eurocode 6)

$f_{k}=3.9 \mathrm{~N} / \mathrm{mm}^{2}$

\subsection{Summary of the test result}

The elastic modulus can be estimated from the compression stage. Based on the ratio between average vertical displacement and average vertical stresses, the measured modulus is approximately equal to $2500 \mathrm{~N} / \mathrm{mm}^{2}$. This corresponds to $450 \mathrm{f}_{\mathrm{k}}$ of the masonry.

Cyclic behaviour of the full system is given on Fig. 3. The figure also shows the envelope of the cyclic curves (in red) as well as a bilinear curve ("elastic-perfectly-plastic") obtained from the envelope by a least square fitting procedure (in green). The behaviour shows a limited hysteretic behaviour most likely due to the opening/closing of the vertical joints.

The maximum loads reached respectively in positive and negative loading are equal to 82.0 and $76.6 \mathrm{kN}$, with maximum drifts of 0.19 and $0.22 \%$ (Displacements are positive in the direction of the wider pier).

The failure mode is illustrated on Figures 4, 5 and 6. Cracking starts in the wider pier for positive loading. This corresponds to a compression in this large wall, induced by the global overturning of the frame system, in combination with significant shear forces (Fig. 6). For negative loading, the failure is triggered by the local compression induced at the lintel support. The ultimate state is reached by excessive cracking at the support, leading to the ejection of the part of the wall located below this crack (Fig. 5).

\subsection{Comparison with theoretical models}

In order to estimate the resistance of this frame system, three different assumptions are consid-

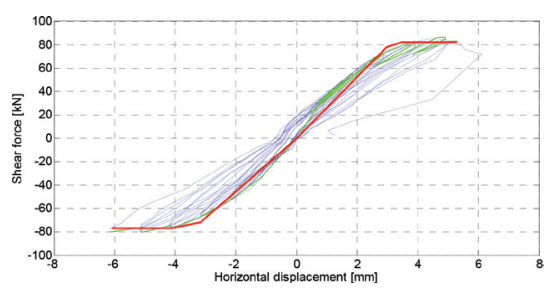

Figure 3. Cyclic behaviour. 


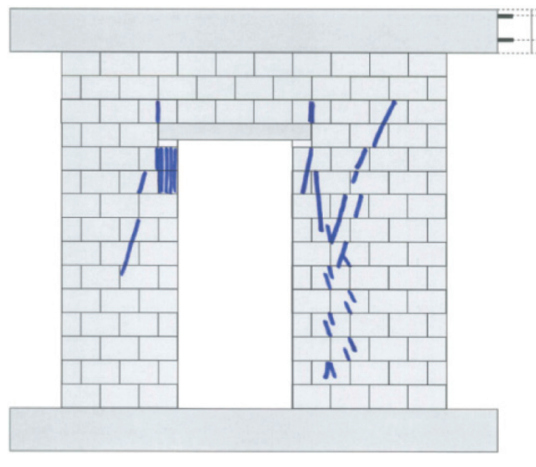

Figure 4. Crack pattern.

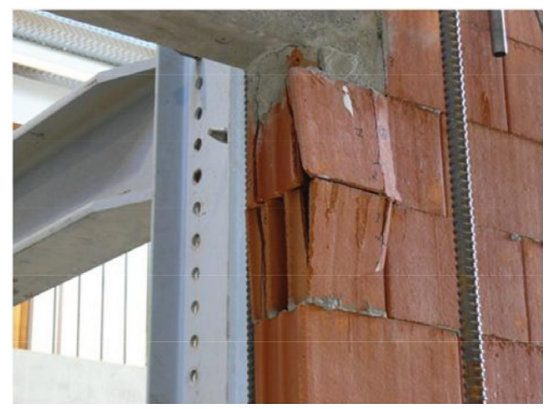

Figure 5. Failure at lintel support.

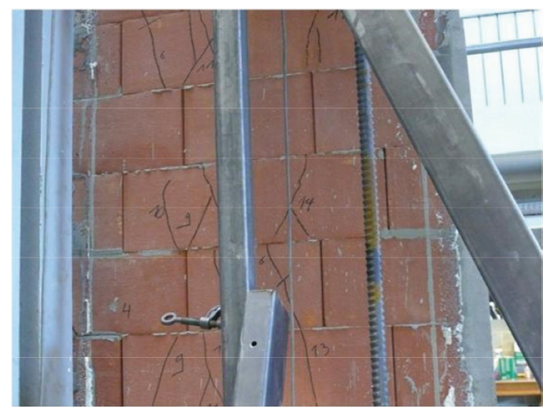

Figure 6. Cracking in the wall.

ered for performing a simplified structural analysis (see Fig. 7). In the first and second assumptions, the system is assumed to behave as two cantilevers, considering that both sides of the opening are coupled in terms of horizontal displacements, but not in terms of rotation (i.e. no frame effect). Assumption 1 is considering a wall height equal to the opening height, while assumption 2 considers the full height of the wall. In the third assumption, a frame effect is taken into account considering the full stiffness of the spandrel. The internal forces (compression, shear and bending) obtained from
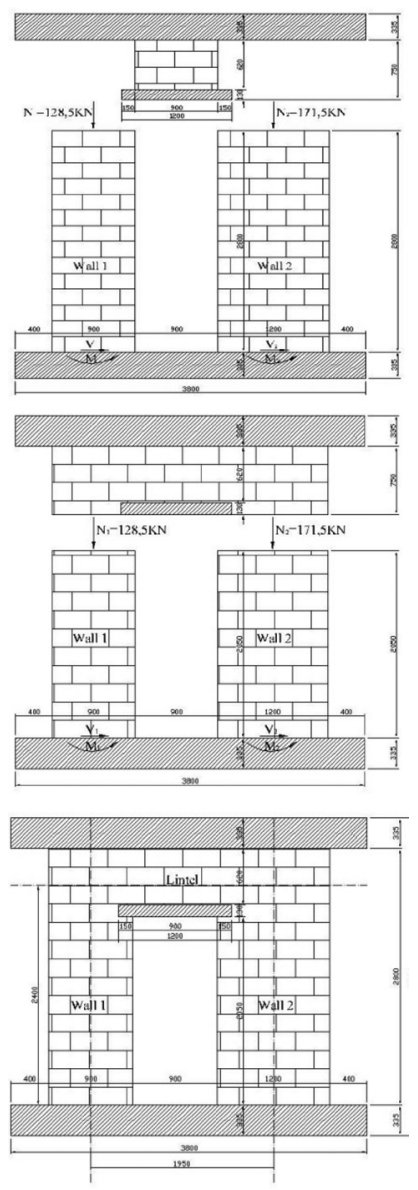

Figure 7. Simple modelling assumptions (long or short cantilever, frame).

these structural analyses are then used as input for a classical EC6 verification. Moreover, for each assumption, it is also considered (i) that the ULS is reached as soon as one of the walls reaches its maximum capacity, or (ii) that a full load redistribution is possible. Results are given in Table 1.

If referring to the experimental results, it can be seen that, regarding the resistance, test results are above the most favourable estimate and that a frame model considering load redistribution provide a safe though reasonably accurate evaluation of the system strength.

\section{EQUIVALENT FRAME MODEL}

This section is dedicated to the comparison of experimental results presented here above with numerical predictions given by TREMURI (Lagomarsino et al, 2013). In this program, the structures 
Table 1. Theoretical assessment acc. EC6.

\begin{tabular}{lll}
\hline & With redistribution & without redistr. \\
\hline $\begin{array}{l}\text { Double } \\
\text { cantilever }\end{array}$ & $46,7 \mathrm{kN}$ & $43,1 \mathrm{kN}$ \\
$\begin{array}{l}\text { Double } \\
\text { cantilever }\end{array}$ & $59,7 \mathrm{kN}$ & \\
Frame & $\begin{array}{l}\text { Limited height } \\
69,0 \mathrm{kN}\end{array}$ & $56,5 \mathrm{kN}$ \\
\hline
\end{tabular}

are modelled using nonlinear macro-elements: each wall, spandrel and lintel is modelled by an equivalent frame element. Piers and spandrels are thus defined as beam elements (in green). These elements are linked together by rigid elements (in blue) whose definition remains based on some subjective criteria. A nonlinear pushover analysis is then performed based on seismic analysis approaches adopted by different codes, among which Eurocode 8.

When resorting to such simplified models, and beside the definition of the material properties (it is here chosen to directly use the experimentally characterized elastic and shear moduli, as well as compressive resistance), the main issues are therefore the way of accounting for the spandrel, lintel and slab behaviour (i.e. all the horizontal elements of the equivalent frame) and the definition of the effective height of the masonry piers (elements represented in green on Figure 8). The height can indeed vary, as shown in Figure 8, resulting in different possible equivalent frames.

As a matter of comparison, the following modelling assumptions are taken into consideration:

- Effective height of the piers equal to (see Figure 8)

- Total height of the wall (i)

- Height of the opening (ii)

- Intermediate height, as automatically generated by the software (iii)

- For case iii, 3 sub-options are also considered:

- Pure masonry spandrel (a)

- Masonry spandrel + RC lintel (b)

- Masonry spandrel + RC lintel and slab (c)

Calculated resistance are summarized in table 2 for loading in positive and negative direction, and compared to experimental results. It can be observed that:

- Default parameters of the software and explicit modelling of all structural elements yield results in extremely good agreement with the experiments in terms of predicted resistance;

- Definition of the effective height of the piers is of limited influence (maximum error of $6 \%$ )

- An omission of any framing element yields conservative results, but the level of conservatism
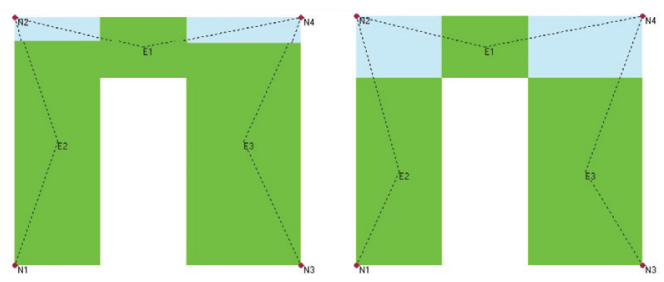

Figure 8. Different modelling assumptions of a frame (cases ii and iii). In green: the deformable frame elements; in blue, the fully rigid connecting elements.

Table 2. Results of the frame analysis.

\begin{tabular}{lll}
\hline Model & Positive loading & Negative loading \\
\hline i.c & $76,8 \mathrm{kN}$ & $72,4 \mathrm{kN}$ \\
ii.c & $85,4 \mathrm{kN}$ & $80,6 \mathrm{kN}$ \\
iii.c & $80,3 \mathrm{kN}$ & $75,9 \mathrm{kN}$ \\
iii.b & $70,1 \mathrm{kN}$ & $67,5 \mathrm{kN}$ \\
iii.a & $46,0 \mathrm{kN}$ & $45,2 \mathrm{kN}$ \\
Exp. & $82,0 \mathrm{kN}$ & $76,6 \mathrm{kN}$ \\
\hline
\end{tabular}

may be rather high (12 to $44 \%$ underestimated results)

Figure 9 shows the approximated bilinear curves obtained with the different models. This figure shows that as soon as the lintel is modelled, the estimation of the global stiffness is reasonably in agreement with the measured values. The modelling of the slab does not seems to be of prime importance to this respect. Figure 9 also evidences one of the most important shortcomings of the equivalent frame approach. The maximum displacement is actually only depending on the drift limit defined by the user. This is done on an experience basis and remains rather arbitrary. The values reached for the reference model (case iii.c) are nevertheless in rather good agreement with the measurements.

\section{REFINED FINITE ELEMENT MODEL}

In order to get an insight into the stress distribution within the masonry wall, an equivalent push-over test is simulated using a two-dimensional refined finite element (FE) model. The mesh is generated using COMSOL Multiphysics (Figure 1), whereas the FE analysis is performed in a custom-developed MATLAB program. The bed joints are assumed rigid whereas the open head joints are modelled as zero-thickness interfaces with zero stiffness. Material parameters are listed in Table 1 and plane stress conditions are assumed. Failure of the bricks is modelled using a simple damage law: 


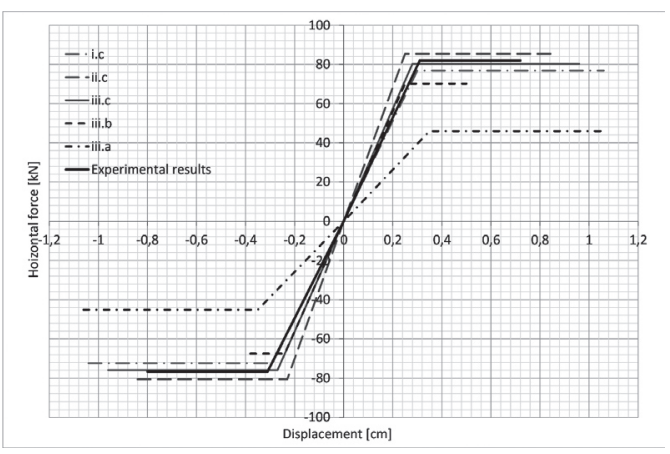

Figure 9. Pushover curves from Tremuri compared to experimental results.

$$
\sigma=(1-\omega) \mathbf{C}_{b} \varepsilon
$$

in which $\boldsymbol{\sigma}$ and $\boldsymbol{\varepsilon}$ are, respectively, the stresses and strains in the bricks, $\mathbf{C}_{\mathrm{b}}$ is the orthotropic constitutive matrix of the bricks, and $\omega$ is a damage parameter varying between zero (no damage) and unity (fully damaged state), which is calculated according to

$$
\omega=1-\frac{\kappa_{0}}{\kappa} \exp \left(-\frac{\kappa-\kappa_{0}}{\gamma}\right)
$$

in which $\gamma$ governs the brittleness (which is calculated using the fracture energy $G_{\mathrm{f}}$, see (Feenstra 2002)), $\kappa_{0}$ is the damage threshold, i.e. the value of the equivalent strain $\varepsilon_{\mathrm{eq}}$ at which damage initiates. $\kappa$ is a history parameter which memorises the maximum value ever attained of the equivalent strain. The latter is governed by a Drucker-Prager criterion fitted to the compressive and shear strengths:

$$
\varepsilon_{\mathrm{eq}}=\alpha \frac{I_{1, \mathcal{\varepsilon}}}{1-2 \nu}+\beta \sqrt{\frac{3 J_{2, \varepsilon}}{(1+\nu)^{2}}}
$$

in which $v$ is Poisson's ratio of the bricks, $I_{1, \varepsilon}$ is the first strain invariant, and $J_{2, \varepsilon}$ is the second deviatoric strain invariant. In Equation 3, the model parameters are calculated according to

$$
\alpha=\frac{f_{\mathrm{c}}-\sqrt{3} f_{\mathrm{s}}}{\sqrt{3} f_{\mathrm{s}}}
$$

and

$$
\beta=\frac{f_{\mathrm{c}}}{\sqrt{3} f_{\mathrm{s}}},
$$

in which $f_{\mathrm{c}}$ and $f_{\mathrm{s}}$ are the compressive and shear strength, respectively.

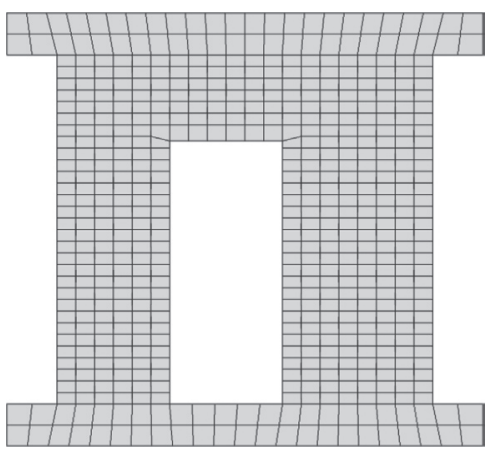

Figure 10. Push-over test (FE approach): finite element mesh.

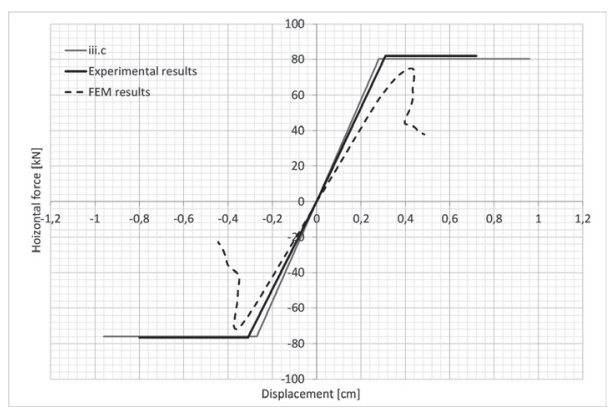

Figure 11. Push-over curves: comparison FEM / exp. / Frame.

An important aspect when modelling damage in quasi-brittle materials such as masonry, is the use of an objective description of strain localisation and failure. It is well known that local damage models (e.g. Eq. 1) will lead to mesh-dependent results, i.e. damage will localise to the smallest numerical entity. Therefore a so-called localisation limiter should be employed, which introduces an objective length scale into the model and governs the volume of localisation. In most continuous masonry models, meshdependency of strain softening is regularised using Cosserat continua (Addessi et al. 2010) or non-local models (Marfia \& Sacco 2012). In this contribution, we use an implicit gradient-enhanced damage model for the objective description of strain localisation and failure (Peerlings et al. 1996). In this model, the history parameter $\kappa$ in Eq. 2 is evaluated using a non-local equivalent strain $\bar{\varepsilon}_{\text {eq }}$ instead of a local equivalent strain, which is calculated according to

$\bar{\varepsilon}_{\mathrm{eq}}-c \nabla^{2} \overline{\mathcal{\varepsilon}}_{\mathrm{eq}}=\varepsilon_{\mathrm{eq}}$

in which $c$ is a length scale parameter which defines an strain averaging domain, see (Peerlings et al. 1996) for more details. 
Table 3. Material parameters for the push-over test.

\begin{tabular}{ll}
\hline Parameter & value \\
\hline $\mathrm{E}_{\mathrm{x}}$ & $2465 \mathrm{~N} / \mathrm{mm}^{2}$ \\
$\mathrm{E}_{\mathrm{y}}$ & $0.5 \mathrm{E}_{\mathrm{x}}$ \\
$G_{\mathrm{xy}}$ & $394 \mathrm{~N} / \mathrm{mm}^{2}$ \\
$v$ & 0.25 \\
$f_{\mathrm{s}}$ & $0.15 \mathrm{~N} / \mathrm{mm}^{2}$ \\
$f_{\mathrm{c}}$ & $3.9 \mathrm{~N} / \mathrm{mm}^{2}$ \\
$G_{\mathrm{f}}$ & $0.04 \mathrm{Nmm} / \mathrm{mm}^{2}$ \\
$\mathrm{c}$ & $400 \mathrm{~mm}$ \\
\hline
\end{tabular}

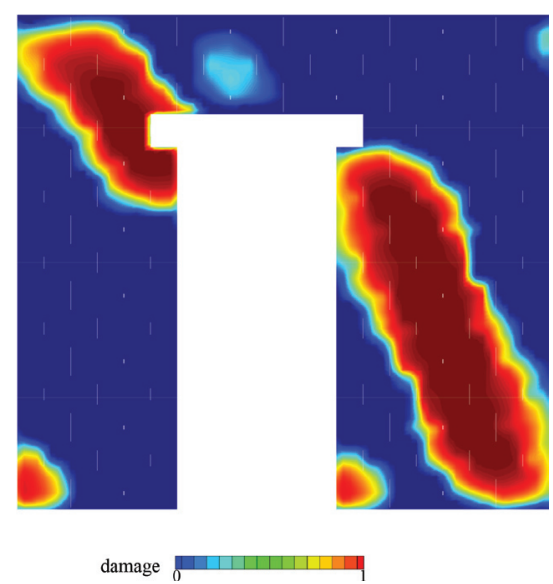

Figure 12. Push-over test (FE approach): damage pattern (loading from the left).

As can be observed from the load-displacement curve, the model is capable of providing a good indication of the peak load of the structure, see Figure 11. However, the stiffness of the model seems more difficult to calibrate and appears actually to be highly sensitive to a number of material parameters. Finally, the damage patterns in Figure 12 indicate that the system exhibited a sheardominant failure mechanism, characterised by shear bands on both sides of the door opening. The FE model predict a rather more brittle failure mode than observed in reality, which could be adjusted by acting on the fracture energy.

\section{CONCLUSIONS}

This contribution presented a comparison of different modelling approaches of a masonry frame, referring also to experimental results. Although this example does not allow to derive very general conclusions, some important features can be pointed out. In particular, it has been proved that using standard values of material parameters together with default modelling schemes provides results that are reasonably in agreement with the experimental observations (not more than $12 \%$ difference). Some specific aspects have also showed out to be of prime importance to get an accurate prediction of the behaviour: when resorting to equivalent frame element, the horizontally framing elements, and in particular the RC lintels have to be represented as realistically as possible, while for $2 \mathrm{D}$ continuous FE models, the fracture energy appear to be the most critical parameter to be properly determined. Further investigations remains however needed to widen these conclusions and be able to make quantified recommendations.

\section{REFERENCES}

Beyer K and Mangalathu S, 2013, Review of strength models for masonry spandrels. Bulletin of Earthquake Engineering, 11:512-542.

da Porto F, Guidi G, Garbin E and Modena C, 2010, InPlane Behavior of Clay Masonry Walls: Experimental Testing and Finite-Element Modeling, Journal of Structural Engineering, 136:1379-1392.

EN 1998-1-1: 2004: Eurocode 8: Design of structures for earthquake resistance - Part 1: General rules, seismic actions and rules for buildings. December 1994.

Karantoni FV and Lirantzaki FN, 2009, Seismic behaviour of "Simple Masonry Buildings" according to EN 1998. 7th International Conference on Earthquake Resistant Engineering Structures, Limassol, North Cypris, 11-12-13 May.

Lagomarsino S, Penna A, Galasco A and Cattari S, 2013, TREMURI program: an equivalent frame model for the nonlinear seismic analysis of masonry buildings. Engineering Structures, 56:1787-1799.

Mordant C, Dietz M, Taylor C and Degée H, 2015a, Seismic behaviour of thin-bed layered unreinforced clay masonry frames with $T$ - or L-shaped piers. In: Seismic Evaluation and Rehabilitation of Structures, eds Alper Ilki and Mochal N. Fardis, Geotechnical, Geological and Earthquake Engineering series, Springer 2015.

Sousa LC, Sousa H, Castro CF, Antonio CC and Sousa R, 2014, A new lightweight masonry block: Thermal and mechanical performance, Archives of civil and mechanical engineering, 14:160-169.

Addessi, D., Sacco, E., \& Paolone, A. 2010. Cosserat model for periodic masonry deduced by nonlinear homogenization. Eur. J. Mech. A/Solids 29:724-737.

Feenstra, P.H. 2002. Implementing an isotropic damage model in Diana. Use-case for the user-supplied subroutine usrmat, In Proceedings of the Third DIANAWorld Conference.

Marfia, S. \& Sacco, E. 2012. Multiscale damage contactfriction model for periodic masonry walls. Comput. Methods Appl. Mech. Engrg. 205-208:189-203.

Peerlings, R.H.J., de Borst, R., Brekelmans, W.A.M., \& de Vree J.H.P. 1996. Gradient-enhanced damage for quasi-brittle materials. Int. J. Numer. Meth. Engrg. 39:3391-3403. 